\title{
Stereotactic radiotherapy in recurrent gynecological cancer: A case series
}

\author{
FRANCESCO DEODATO $^{1}$, GABRIELLA MACCHIA ${ }^{1}$, LUCA GRIMALDI ${ }^{2}$, GABRIELLA FERRANDINA ${ }^{3,4}$, \\ DOMENICA LORUSSO ${ }^{4}$, VANDA SALUTARI ${ }^{3}$, SAVINO CILLA ${ }^{2}$, VINCENZO VALENTINI ${ }^{5}$, NUMA CELLINI ${ }^{5}$, \\ ANGELO PIERMATTEI ${ }^{2}$, GIOVANNI SCAMBIA ${ }^{4}$ and ALESSIO GIUSEPPE MORGANTI ${ }^{1}$ \\ ${ }^{1}$ Radiotherapy Unit, ${ }^{2}$ Medical Physics, ${ }^{3}$ Gynaecologic Oncology Unit, 'John Paul II' Center for High Technology \\ Research and Education in Biomedical Sciences, Catholic University, I-86100 Campobasso; \\ Departments of ${ }^{4}$ Gynaecology and ${ }^{5}$ Radiotherapy, Catholic University, Rome, Italy
}

Received January 9, 2009; Accepted April 2, 2009

DOI: 10.3892/or_00000453

\begin{abstract}
Scarce data are available on the use of extracranial stereotactic radiotherapy in recurrent gynecological tumors. The aim of this report was to analyze the results of our preliminary experience with extracranial stereotactic radiotherapy in locally or distantly recurrent gynecological tumors. Extracranial stereotactic radiotherapy was planned by the Precise-Plan treatment planning system. Patients were immobilized using the Stereotactic Body-Frame. Five consecutive daily fractions were delivered; dose/ fraction and total dose were defined based on an institutional doseescalation protocol. A class solution with 4 non-coplanar fixed beams based on the tetrad configuration was used in all patients. Eleven patients (12 lesions), were included in the analysis. Stereotactic radiotherapy was delivered as first radiotherapy treatment (5 patients), or as retreatment (6 patients). Complete clinical response was achieved in $8 / 12$ lesions $(66.6 \%)$, while partial response was documented in $2 / 12$ lesions (16.6\%). With a median follow-up of 19 months (range, 2-37 months), 7 patients (63\%) experienced local and/or distant progression of disease. The 2-year local progression-free survival was $81.8 \%$, while the 2 -year metastases-free survival was $54.4 \%$. The 2 -year overall survival was $63.6 \%$. Acute and late toxicities were grade 2 or less. There was no difference in quality of life scores between the data collected before extracranial stereotactic radiotherapy and at first follow-up evaluation. Fractionated extracranial stereotactic radiotherapy administered up to a
\end{abstract}

Correspondence to: Dr Gabriella Macchia, Radiotherapy UnitDepartment of Oncology, Catholic University, Largo A. Gemelli 1, I-86100 Campobasso, Italy

E-mail: gmacchia@rm.unicatt.it

Key words: extracranial stereotactic radiotherapy, gynaecological tumor, recurrence, radiotherapy dose of $30 \mathrm{~Gy}$ in five fractions is well tolerated. Further studies of extracranial stereotactic radiotherapy and novel radiotherapy techniques are warranted in the challenging setting of recurrent gynecological tumors.

\section{Introduction}

Gynecological tumors are burdened with a variable incidence of locoregional recurrence, which are often treated by radical surgery and/or combined chemoradiation $(1,2)$. However, both approaches show a limited effectiveness, mainly due to previous treatment, in particular radiotherapy. Therefore, prognosis remains poor as in distant recurrence.

Extracranial stereotactic radiotherapy (ESRT) allows the irradiation of thoraco-abdomino-pelvic targets with high doses of irradiation in a single or a few sessions with extremely high precision (3). ESRT has been tested in various settings (4-11), although, there is no agreement as for the dose (total or per fraction) (12), or for the most suitable therapeutic settings in which it should be employed (13). Treatment of abdomino-pelvic (4-6), thoracic $(7,11)$, and renal tumors (8), resulted in 80,90 and $95 \%$ rates of local control, respectively. Encouraging results have also been published in several series of metastatic lung tumors, nasopharyngeal recurrence, and spinal metastasis (14-16).

At present, there are no data in the literature on the outcome of ESRT treatment of recurrence from gynecological tumors (RGT) except for some experiences with fractionated stereotactic radiotherapy boost as an alternative to brachytherapy (9).

In our Center, an ESRT phase I clinical trial is ongoing, including patients enrolled in 7 different arms, based on tumor site, and previous treatment such as lung intraparenchymal tumors, paramediastinal or near the chest wall tumors, extrathoracic tumors, patients with pancreatic or pelvic tumors retreated with $\leq 60$ Gy or $>60$ Gy dose, patients receiving a boost after prior radiotherapy with $\leq 50 \mathrm{~Gy}$ or $>50 \mathrm{~Gy}$ dose.

This study reports the preliminary results in terms of toxicity and response, of our ESRT experience with local or distant RGT. 


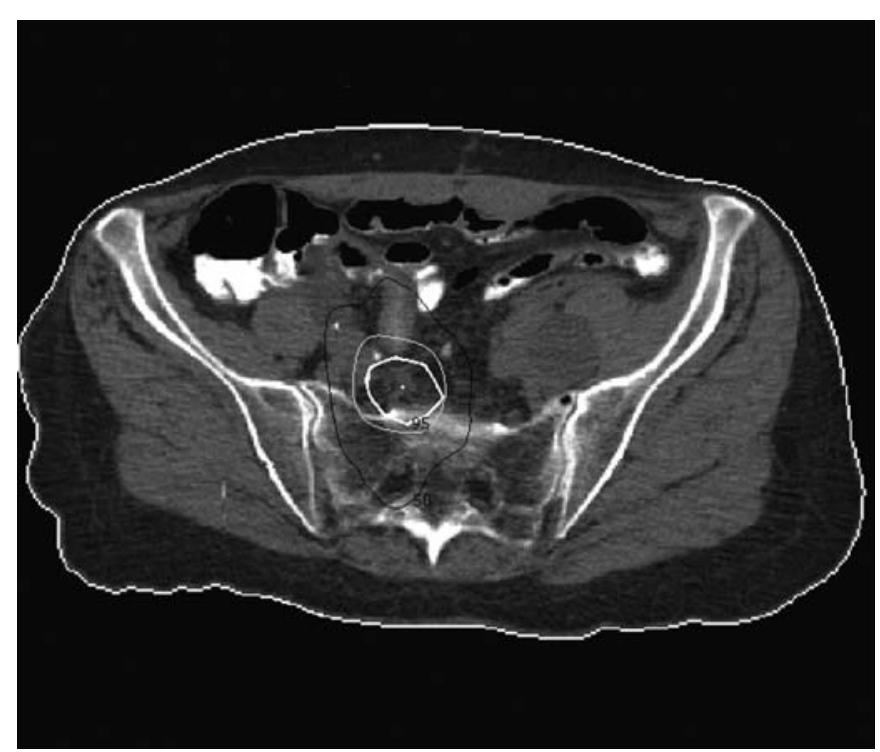

Figure 1. Axial view of a radiosurgical treatment plan for one of the patients treated in the study. The structure outlined in white is the tumor volume. The gray and the black lines represent the $50 \%$, and the $95 \%$ isodose lines, respectively.

\section{Materials and methods}

Eligibility. The study was approved by the Institutional Review Board, and informed consent was obtained from all patients. Patients who entered the study were enrolled from June 2005 to May 2007. All patients showed local or distant recurrence from gynecological tumors, and all but one had been previously treated with surgery, chemotherapy or radiotherapy.

Treatment planning. Treatment set-up was performed with CT-simulator and customized body-frame immobilization (Elekta Stereotactic Body-Frame or SBF, Elekta Oncology Systems, Crawley, UK). Three CT-simulations were performed to verify the reproducibility of patient positioning. The definitive CT simulation for stereotactic localization and treatment plan implementation was carried out with the spiral technique. Three-mm thick with 3-mm gap between scans at the target level, and 10-mm thick with $10-\mathrm{mm}$ gap between scans outside the target were acquired. For organ motion measurement caused by respiratory movements, before definitive acquisition, 30 consecutive $\mathrm{CT}$ scans were performed on the same axial slice $(1 \mathrm{scan} / \mathrm{sec})$. Patients with abdomino-pelvic targets ingested $2 \mathrm{cc}$ of contrast medium (Gastrografin) diluted in half a liter of water to visualize the small intestine. ESRT was planned by the Precise-Plan treatment planning system (Elekta Precise, Elekta Oncology Systems, Crawley, UK). The GTV was defined using CT \pm MRI \pm CT-PET. The CTV was defined as the GTV. An anisotropic CTV to PTV margin (at least $10 \mathrm{~mm}$ ) was added based on organ motion and set-up errors. A class solution with 4 non-coplanar fixed photon beams (plus 1-2 beams for isocenter verification) based on the tetrad configuration was used in all patients $(17,18)$. The ESRT dose was prescribed to the isocenter (Fig. 1). According to ICRU 60 the following constraints were used for the PTV: Dmin $\geq 95 \%$; Dmax $\leq 107 \%$. Five consecutive daily fractions were delivered; dose/fraction and total dose were defined based on an institutional dose-escalation protocol. In all patients daily portal images in the first phase of irradiation (5-10 MV) were acquired on all beams. Deviations $>3 \mathrm{~mm}$ in the isocenter position were immediately corrected.

Toxicity and response evaluation. Patients underwent personalized support therapy based on the irradiated anatomical district. RTOG and RTOG/EORTC scales (19) were used to score acute and late toxicity, respectively. The clinical response was evaluated according to WHO recommendations (20). Two to 3 months after the end of ESRT, patients were evaluated for objective response based on clinical examination, CT scan, MRI and/or PET. Locoregional recurrence was classified as follows: 'in-field' if over $95 \%$ of recurrence volume received at least $95 \%$ of prescribed dose; 'out-of-field' if $<20$ of recurrence volume received $95 \%$ of prescribed dose; 'marginal' (or 'extending outside the field') if $95 \%$ of prescribed dose was delivered to $20-95 \%$ of recurrence volume. Follow-up evaluation including clinical and radiological examination was repeated every 6 months.

Quality of life (QoL) evaluation. Several parameters were recorded to evaluate the ESRT impact on pain, ECOG, weight and QoL. The CLAS score was used to evaluate quality of life (CLAS1), level of energy (CLAS2) and ability to undertake daily activities (CLAS3), both before and after (3-4 weeks) radiotherapy. Patients scored their perceptions of these symptoms by placing a mark on a $100-\mathrm{mm}$ line to indicate magnitude of the symptom (21). The visual analog scale (VAS) for pain, the Pain score (pain evaluation obtained by multiplying severity $\mathrm{x}$ frequency) and the Drugs score (analgesic assumption evaluation obtained by multiplying severity $\mathrm{x}$ frequency) were used to record and monitor pain (22). The weight and ECOG score of patients before and after (3-4 weeks) ESRT were recorded by nursing staff.

Statistical analysis. The statistical analysis was performed with SYSTAT, version 11.0 (SPSS, Chicago, IL). Wilcoxon signed rank test was used to compare Quality of Life parameters before and after ESRT. Overall survival (OS), local progression-free survival (LPFS), and metastasis-free survival (MFS) rates were calculated using the Kaplan-Meier method (23). OS was calculated from the date of ESRT to the date of death or date of last visit, LPFS was calculated from the date of ESRT to the date of local relapse or date last seen and MFS was calculated from the date of ESRT to the date of relapse or date last seen.

\section{Results}

Eleven patients (12 lesions), median age: 66 years (range 5184), ECOG score: 0-2, were included in the analysis. Table I reports the characteristics of the whole study population, previous treatment, ESRT sites and doses, toxicity data, responses at ERT site, and outcome. Four patients received only one line of chemotherapy, 2 patients received 2 lines, and 1 patient received 3 lines before ESRT. Stereotactic radiotherapy was delivered as first radiotherapy treatment 
Table I. Characteristics of the whole study population.

\begin{tabular}{|c|c|c|c|c|c|c|c|c|c|c|}
\hline $\begin{array}{l}\text { No. of } \\
\text { patient }\end{array}$ & $\begin{array}{l}\text { Primary tumor } \\
\text { (histotype) }\end{array}$ & $\begin{array}{l}\text { Previous } \\
\text { treatment }\end{array}$ & $\begin{array}{c}\text { Previous } \\
\text { RT dose } \\
\text { (Gy) }\end{array}$ & ESRT site & $\begin{array}{l}\text { ESRT dose/ } \\
\text { fraction } \\
(\mathrm{Gy})\end{array}$ & $\begin{array}{l}\text { Acute } \\
\text { toxicity grade }\end{array}$ & $\begin{array}{l}\text { Late } \\
\text { toxicity } \\
\text { grade }\end{array}$ & $\begin{array}{l}\text { Response } \\
\text { at ESRT } \\
\text { site }\end{array}$ & Site of failure & Outcome \\
\hline 1 & $\begin{array}{l}\text { Ovarian } \\
\text { (serous) }\end{array}$ & $\mathrm{S}-\mathrm{C}$ & & Presacral lymph nodes & $30 / 6$ & 0 & 0 & $\mathrm{CR}$ & - & $\mathrm{NED}$ at $37 \mathrm{mts}$ \\
\hline 2 & $\begin{array}{l}\text { Ovarian } \\
\text { (adenocarcinoma) }\end{array}$ & $\mathrm{S}-\mathrm{C}$ & & Hepatic segment IV & $30 / 6$ & 0 & 0 & $\mathrm{CR}$ & $\mathrm{D}$ & $\mathrm{NED}$ at $31 \mathrm{mts}^{\mathrm{a}}$ \\
\hline 3 & $\begin{array}{l}\text { Ovarian } \\
\text { (adenocarcinoma) }\end{array}$ & S-C-R & 37.5 & $\begin{array}{l}\text { Left supraclavicular lymph } \\
\text { nodes }\end{array}$ & $25 / 5$ & $\begin{array}{l}1 \text { Skin erithema, } \\
\text { mild pharingitis }\end{array}$ & 0 & $\mathrm{CR}$ & - & $\mathrm{NED}$ at $19 \mathrm{mts}$ \\
\hline 4 & $\begin{array}{l}\text { Ovarian } \\
\text { (serous) }\end{array}$ & $\mathrm{C}$ & & $\begin{array}{l}\text { i) Anterior mediastinal } \\
\text { lymph nodes }\end{array}$ & $30 / 6$ & $\begin{array}{l}2 \text { Asymptomatic } \\
\text { pneumonitis }\end{array}$ & 0 & $\begin{array}{l}\text { CR on } \\
\text { both }\end{array}$ & $\mathrm{D}$ & AWD at $18 \mathrm{mts}$ \\
\hline & & & & $\begin{array}{l}\text { ii) Left internal mammary } \\
\text { chain lymph nodes }\end{array}$ & & & & lesions & & \\
\hline 5 & $\begin{array}{l}\text { Cervical } \\
\text { (epidermoidal) }\end{array}$ & CRT & 50 & Right inguinal lymph nodes & $30 / 6$ & 0 & 0 & PR & - & $\mathrm{NED}$ at $16 \mathrm{mts}^{\mathrm{b}}$ \\
\hline 6 & $\begin{array}{l}\text { Cervical } \\
\text { (epidermoidal) }\end{array}$ & $S$ & & Vagina & $30 / 6$ & $\begin{array}{l}2 \text { Skin and vaginal } \\
\text { mucosal eritema }\end{array}$ & 2 & $\mathrm{CR}$ & - & $\mathrm{NED}$ at $28 \mathrm{mts}$ \\
\hline 7 & $\begin{array}{l}\text { Cervical } \\
\text { (epidermoidal) }\end{array}$ & C-CRT & 65 & Uterine cervix & $25 / 5$ & 0 & 1 & $\mathrm{CR}$ & - & $\mathrm{NED}$ at $19 \mathrm{mts}$ \\
\hline 8 & $\begin{array}{l}\text { Cervical } \\
\text { (epidermoidal) }\end{array}$ & CRT & 50.4 & Presacral lymph nodes & $30 / 6$ & 2 Proctitis & 0 & $\mathrm{CR}$ & $\mathrm{D}$ & DOD at $11 \mathrm{mts}$ \\
\hline 9 & $\begin{array}{l}\text { Uterine } \\
\text { (adenocarcinoma) }\end{array}$ & R-BRT & 63 & $\begin{array}{l}\text { Right internal iliac lymph } \\
\text { nodes }\end{array}$ & $30 / 6$ & 0 & 0 & PR & $\begin{array}{l}\mathrm{L} \text { (marginal } \\
\text { recurrence) }\end{array}$ & DOD at $28 \mathrm{mts}$ \\
\hline 10 & $\begin{array}{l}\text { Uterine } \\
\text { (carcinosarcoma) }\end{array}$ & - & & Right adrenal gland & $30 / 6$ & 2 Vomiting & NE & SD & $\mathrm{D}$ & DOD at $2 \mathrm{mts}$ \\
\hline 11 & $\begin{array}{l}\text { Uterine } \\
\text { (carcinosarcoma) }\end{array}$ & S-C-R & 45 & $\begin{array}{l}\text { Right common iliac lymph } \\
\text { nodes }\end{array}$ & $20 / 4$ & 2 Nausea & 0 & PD & $\mathrm{D}+\mathrm{L}$ (in field) & DOD at $8 \mathrm{mts}$ \\
\hline
\end{tabular}

S, surgery; R, radiotherapy; C, chemotherapy; CRT, concurrent chemoradiation; BRT, brachytherapy; CR, complete response; PR, partial response; SD, stable disease; PD, progression of disease; NE, not evaluable; NLE, not locally evaluable; L, local recurrence; D, distant metastases; NED, no evidence of disease; DOD, dead of disease; AWD, alive with disease. ${ }^{a}$ Patient had pelvic progression at 2 months. She was treated with chemotherapy and then achieved a clinical complete response. ${ }^{b}$ Patient died at 16 months for intercurrent disease (2 metachronous cancers).

(5 patients), or as re-treatment (6 patients). The treated GTV ranged from $0.1 \mathrm{cc}$ to $190.0 \mathrm{cc}$ (mean, $31.5 \mathrm{cc}$; median, $24.4 \mathrm{cc})$. The treated PTV ranged from $4.0 \mathrm{cc}$ to $273.0 \mathrm{cc}$ (mean, $68.0 \mathrm{cc}$; median, $42.0 \mathrm{cc}$ ). The dose/volume constraints were respected in all patients.

All patients were available for response: complete clinical response was achieved in 8/12 lesions $(66.6 \%)$, while partial response was documented in $2 / 12$ lesions $(16.6 \%)$ for an overall response rate of $83.3 \%$. One stable disease $(8.3 \%)$ and only one local progression $(8.3 \%)$ were observed, both after 2 months from the completion of ESRT. Fig. 2 shows an example of complete response at CT scan evaluation.

With a median follow-up of 19 months (range, 2-37 months) in the overall series, 7 patients $(63 \%)$ experienced local and/or distant progression of disease: in particular, 1 patient had only local progression, 1 patient experienced both local and distant progression ('in field' progression at 2 months concomitant with lung metastasis), while 4 patients showed only distant progression of disease. As far as local progressionfree survival (expressed considering the ESRT treated lesions) is concerned, the 2-year LPFS was $81.8 \%$, while the 2-year MFS was $54.4 \%$ as shown in Fig. 3.
Five patients have died (4 cancer related deaths at 2, 8, 11 and 28 months, respectively, and 1 intercurrent death at 16 months), as summarized in Table I; the 2-year OS was $63.6 \%$.

Finally, we evaluated the clinical outcome in the subgroup ( 7 patients, 8 lesions) treated at the highest dose level (i.e., 30/6 Gy). Complete clinical response was documented in $6 / 8$ lesions $(75.0 \%)$, with an overall response rate of $100 \%$. The 2-year LPFS was $87.5 \%$ and, with the limits inherent in the small series, seems to be more favorable compared to the remaining population (87.5 vs. $66.7 \%$, respectively). Overall, in the 30/6 Gy group median MFS was 7 months, with a 2 -year MFS of $50 \%$.

One patient died immediately after restaging, thus leaving 10 patients evaluable for the assessment of late toxicity: 1 patient showed grade 2 late toxicity on vaginal mucosa, and 1 patient developed grade 1 late toxicity on rectal mucosa (teleangectasies documented at rectoscopy, not requiring supportive therapy). However, it should be noted that this patient had been previously irradiated (65 Gy) on pelvic volume.

All patients were studied for quality of life using CLAS score system, VAS, and clinical parameters as pain score, 


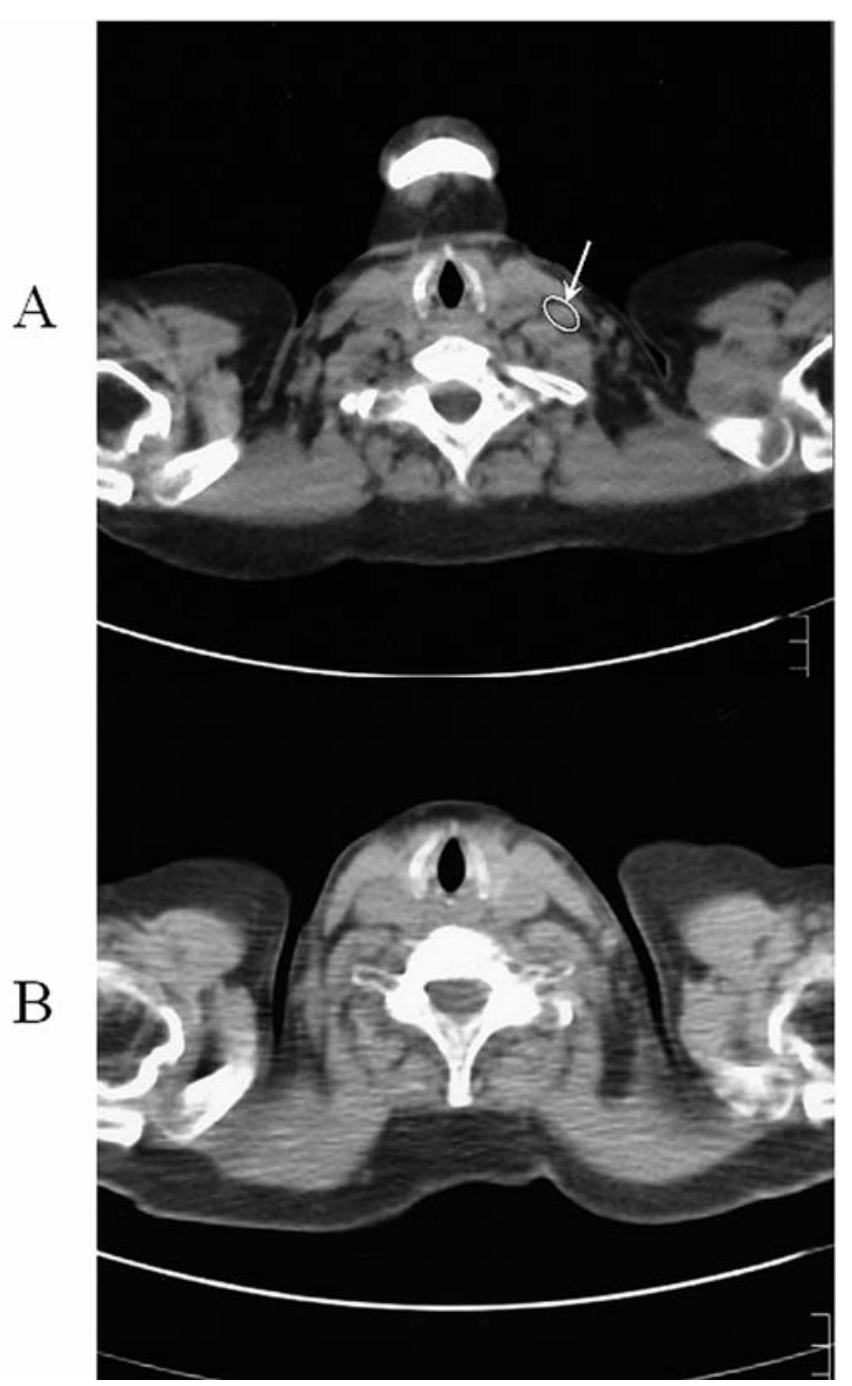

Figure 2. CT scans on the left supraclavicular metastatic lymph node (patient no. 3) before (A) and after (B) stereotactic treatment.

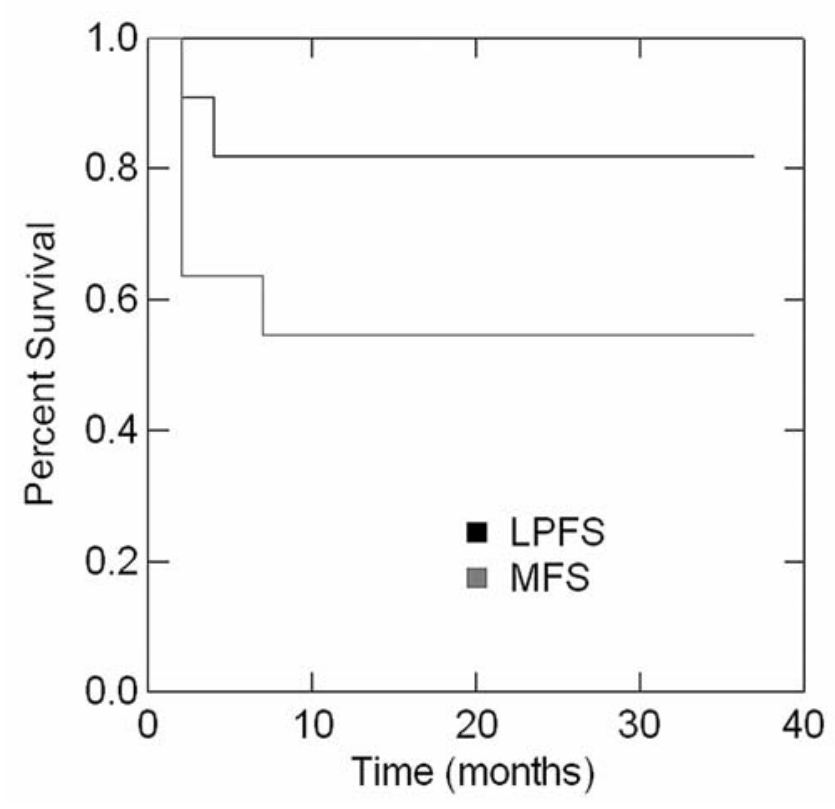

Figure 3. Local progression-free survival (LPFS) and metastases-free survival (MFS) curves in the overall series. drug score and weight. There was no difference in CLAS, and VAS scores, neither in clinical parameters between the data collected before ESRT and at first follow-up evaluation (data not shown).

\section{Discussion}

Recurrence from gynecological tumors are usually treated for palliation considering the drawbacks of surgery and radiotherapy. The only feasible therapy is usually chemotherapy (24), however, the results in terms of response and outcome are generally limited, especially in patients undergoing previous chemotherapy.

To the best of our knowledge, this series represents the first report on clinical activity and toxicity of ESRT in RGT. We documented a $83.3 \%$ overall response rate, and a $66.6 \%$ complete response rate which represent in our opinion very encouraging results when considering that 8 patients in the overall series, and all ovarian cancer patients had already been treated with chemotherapy. These data confirm previous observations reported in other abdomino-pelvic neoplasms (2-4).

The therapeutic approach of RGT is often complicated by the consequences of previous surgery and/or chemotherapy and/or radiotherapy. Although 8 patients in this series were pretreated with chemotherapy and/or radiotherapy (6 patients) and/or surgery (5 patients), fractionated ESRT was well tolerated: indeed, no patient showed grade $>2$ acute toxicity or $>2$ late toxicity. Moreover, analysis of fatigue related indicators and clinical data before and after ESRT showed that ESRT was not associated with any detrimental effects.

It has to be taken into account that although the cases included in this series really represent a very poor prognosis patients, therefore likely to be excluded from conventional treatments, the 2-year LPFS was of $81.8 \%$, and more important, $54.5 \%$ of patients still showed no evidence of residual disease after ESRT at time of outcome analysis.

Based on these preliminary results, we conclude that ESRT might represent a promising palliation treatment strategy for RGT, so that a systematic evaluation of its clinical efficacy also in combination with systemic approaches is worth further investigation. In particular, in patients with oligometastatic disease, the possibility to add chemotherapy for control of infraclinical disease to ESRT, being the latter able to act at sites of macroscopic disease, is an appealing working hypothesis (25).

\section{References}

1. Van Wijk FH, Huikeshoven FJ, Abdulkadir L, et al: Recurrent endometrial cancer: a retrospective study. Eur J Obstet Gynecol Reprod Biol 130: 114-120, 2007.

2. Elst P, Ahankour F and Tjalma W: Management of recurrent cervical cancer. Review of the literature and case report. Eur J Gynaecol Oncol 28: 435-441, 2007.

3. Potters L, Steinberg M, Rose C, et al: American Society for Therapeutic Radiology and Oncology and American College of Radiology practice guidelines for the performance of stereotactic body radiation therapy. Int J Radiat Oncol Biol Phys 60: 1026-1032, 2004.

4. Wulf J, Haedinger U, Oppitz U, et al: Stereotactic boost irradiation for targets in abdomen and pelvis. Radiother Oncol 70: 31-36, 2004. 
5. Wulf J, Guckemberger M, Haedinger U et al: Stereotactic radiotherapy of primary liver cancer and hepatic metastases. Acta Oncol 45: 838-847, 2006.

6. Madsen BL, Hsi RA, Pham HT, et al: Stereotactic hypofractionated accurate radiotherapy of the prostate (SHARP), 33.5 Gy in five fractions for localized disease: first clinical trial results. Int J Radiat Oncol Biol Phys 67: 1099-1105, 2007.

7. Nagata Y, Matsuo Y, Takayama K, et al: Current status of stereotactic radiotherapy for lung cancer. Int J Clin Oncol 12: 3-7, 2007.

8. Werfall PJ, Blomgren H, Lax I, et al: Extracranial stereotactic radiotherapy in primary and metastatic renal cell carcinoma. Radioth Oncol 77: 88-95, 2005

9. Molla M, Escude L, Nouet P, et al: Fractionated stereotactic radiotherapy boost for ginecologic tumors: an alternative to brachytherapy? Int J Radiat Oncol Biol Phys 62: 118-124, 2005

10. Bogart JA: Stereotactic body radiotherapy for poor-risk lung cancer: 'more cyber, less knife?' Cancer J 13: 75-77, 2007.

11. Brown WT, Wu X, Amendola B, et al: Treatment of early nonsmall cell lung cancer, stage IA, by image-guided robotic stereotactic radioablation - CyberKnife. Cancer J 13: 87-94, 2007.

12. Kavanagh BD, McGarry RC and Timmerman R: Extracranial radiosurgery stereotactic body radiation therapy) for oligometastases. Semin Radiat Oncol 16: 77-84, 2006.

13. Timmerman RD and Story M: Stereotactic body radiation therapy: a treatment in need of basic biological research. Cancer J 12: 19-20, 2006.

14. Salazar OM, Sandhu TS, Lattin PB, et al: Once-weekly, highdose stereotactic body radiotherapy for lung cancer: 6-year analysis of 60 early-stage, 42 locally advanced, and 7 metastatic lung cancers. Int J Radiat Oncol Biol Phys 72: 707-715, 2008.

15. Chua DT, Wei WI, Sham JS, et al: Stereotactic radiosurgery versus gold grain implantation in salvaging local failures of nasopharyngeal carcinoma. Int J Radiat Oncol Biol Phys 69: 469-474, 2007.
16. Chang EL, Shiu AS, Mendel E, et al: Phase I/II study of stereotactic body radiotherapy for spinal metastasis and its pattern of failure. J Neurosurg Spine 7: 151-160, 2007.

17. Sailer SL, Rosenman JG, Symon JR, et al: The tetrad and hexad: maximum beam separation as a starting point for noncoplanar 3D treatment planning: prostate cancer as a test case. Int J Radiat Oncol Biol Phys 30: 439-446, 1994.

18. Papiez L, Timmerman R, DesRosiers C and Randall M: Extracranial stereotactic radioablation: physical principles. Acta Oncol 42: 882-894, 2003.

19. Perez CA and Brady LW: Overview. In: Principles and Practices of Radiation Oncology. 2nd edition. Perez CA and Brady LW (eds). Lippincott Company, Philadelphia, PA, pp163, 1992 .

20. Miller AB, Hoogstraten B, Staquet M and Winkler A: Reporting results of cancer treatment. Cancer 47: 207-214, 1981.

21. Sutherland HJ, Walker P and Till JE: The development of a method for determining oncology patients' emotional distress using linear analogue scales. Cancer Nurs 11: 303-308, 1988

22. Salazar OM, Sandhu T, Da Motta NW, et al: Fractionated halfbody irradiation HBI) for the rapid palliation of widespread, symptomatic, metastatic bone disease: a randomized Phase III trial of the International Atomic Energy Agency (IAEA). Int J Radiat Oncol Biol Phys 50: 765-775, 2001.

23. Kaplan EL and Meier P: Non-parametric estimation from incomplete observations. J Am Statist Assoc 53: 457-481, 1985.

24. Pectasides D, Kamposioras K, Papaxoinis G and Pectasides E: Chemotherapy for recurrent cervical cancer. Cancer Treat Rev 34: 603-613, 2008.

25. Rubin P, Brasacchio R and Katz A: Solitary metastases: illusion versus reality. Semin Radiat Oncol 16: 120-130, 2006. 